\title{
Fostering Indigenous Students' Participation in Business Education
}

\begin{tabular}{c|c} 
Peter Vitartas & Kurt Ambrose \\
$\begin{array}{c}\text { La Trobe Business School, La Trobe University } \\
\text { p.vitartas@latrobe.edu.au }\end{array}$ & $\begin{array}{c}\text { La Trobe Learning and Teaching, La Trobe } \\
\text { University }\end{array}$ \\
\hline Hayley Millar & k.ambrose@latrobe.edu.au \\
\hline $\begin{array}{c}\text { College of Arts, Social Sciences and } \\
\text { Commerce, La Trobe University } \\
\text { h.millar@latrobe.edu.au }\end{array}$ & $\begin{array}{c}\text { Thi Kim Anh Dang } \\
\text { Office of the Vice-Provost (Learning and } \\
\text { Teaching), Monash University } \\
\text { kimanh.dang@monash.edu }\end{array}$ \\
\hline
\end{tabular}

Keywords: business higher education, low socioeconomic status, disadvantaged students, participation and engagement.

\section{Introduction}

In the Australian higher education context Indigenous students have consistently been underrepresented in business education compared to other disciplines, such as education and arts, and compared to non-Indigenous students. According to Asmar, Page and Radloff (2011).

"Compared with non-Indigenous students, Indigenous students... were more likely to be studying in the humanities; slightly more likely to be studying education, in a field of health, or in the creative arts; and less likely to be studying science, engineering or business" (p. 4).

Progress on participation rates in business education has been slow as evidenced by Schwab making similar observations of the pattern of Indigenous participation in higher education in 1996 (Schwab 1996).

The literature has revealed various attempts to increase overall Indigenous commencement and completion rates at universities (see e.g., Asmar et al., 2011; Barney, 2013; Behrendt et al., 2012; Raciti et al., 2014; Rahman, 2013). Nevertheless, little research has been undertaken on the topic of improving the uptake of higher education in business courses in particular (see Behrendt et al., 2012 and Rkein \& Norris 2012 for exceptions). Among various measures, fostering Indigenous students' participation in business education is 'crucial for [indirectly] fostering [economic] independence' (Foley, 2013, p. 25) and required if more Indigenous businesses are to be created.

Against this backdrop, this paper contributes to our understanding of the complex issue of Indigenous students' participation in business education. It begins by providing a brief review of the literature exploring enrolment and completion rates in business disciplines at the tertiary level. The paper then presents a case study of an innovative intervention developed by an Australian higher educational institution designed to inspire young Indigenous students to consider tertiary business studies as a viable option which would result in a positive disposition toward tertiary education. Drawing on the activities and review of the artefacts generated from 
the project and in light of the literature, the paper crystalizes key elements of the innovative approach that deemed it successful. Apart from the theoretical contributions, the findings also have implications for other higher education contexts aiming to improve Indigenous participation in business education.

\section{Literature Review}

The engagement and participation rates of Indigenous people all levels of education, high school and higher education have been found to be comparatively low when compared to the wider population, (see e.g., ABS, 2012; Asmar et al., 2011; Biddle, 2010; Schwab, 2006) and across all sectors of higher education (Andersen, Bunda, \& Walter, 2008) including business education (see Behrendt et al., 2012; Rkein \& Norris, 2012). Recent figures indicate that Indigenous represent just under $1 \%$ of all domestic students undertaking study in higher education and can be compared to the population representing around $2.5 \%$ of the all Australians (Dept. of Education 2013).

In terms of broad study areas Indigenous student preferences are for Society and Culture, followed by Health then Education by size. Management and Commerce has the fourth largest number of Indigenous students, however this represents only $10.2 \%$ of students and is compared to $24.7 \%$ of all students who were studying Management and Commerce (Dept. of Education 2013).

\section{Barriers to participation in higher education}

According to Asmar, Page and Radloff (2011), 'Indigenous students are more likely... to be of lower socioeconomic status... to be older... to come from provincial or remote areas and somewhat more likely to be the first in their family to attend university' (p. 3). These demographic, economic, geographic, and cultural factors together with social capital have been found to impact 'students' perceptions, choices and decisions about participation in higher education' (Wilks \& Wilson, 2012, p. 79). Financial hardship (Bradley, et al., 2008; Pechenkina \& Anderson, 2011), the fact of being first in their family to attend university (Barney, 2013; Behrendt et al., 2012), a lack of university readiness (Hossain et al., 2008; McKay \& Devlin, 2014) and disadvantages from living in remote areas (Rkein \& Norris, 2012) also appear to be major barriers to participation and completion of higher education for Indigenous students. These factors are interrelated in their impact on participation in higher education. For example, like other students from low SES backgrounds, Indigenous students often enter higher education "with little familiarity with academic culture and discourses and, as a result, they can feel illprepared and out of place" (McKay \& Devlin, 2014, p. 1). Being newcomers to university and being the first in the family to attend university, students may find this challenge daunting and difficult to handle.

Deep seated barriers to Indigenous participation and engagement at university are especially related to cultural issues and a "hidden curriculum" (Rahman, 2013) dominated by Western practices and ways of knowing, lack of cultural safety in higher education institutions and complex issues involving educational pathways. Indigenous knowledge and the teaching of cultural studies have been found to be excluded or marginalised in the curriculum (Barney, 2013; Rahman, 2013) by Western knowledge systems. Likewise sociocultural values clash in terms of teaching styles, pedagogies and course content (Pechenkina et al., 2011; Rkein \& Norris, 2012). This clash can present as an insurmountable barrier when Indigenous students have to "acquire [Western] school cultural knowledge and succeed in education, at the expense of their cultural identity, practices and world views" (Rahman, 2013, p. 664). The differences between Western 
and Indigenous knowledge systems in the hidden curriculum could turn attending university into a culturally and socially isolating experience for many Indigenous students (Barney, 2013; Pechenkina et al., 2011), leading to a lack of cultural safety for them. The problem exacerbates when overall a very small pool of Indigenous students makes it to university (Chirgwin, 2014).

\section{Barriers to participation in business education}

A number of issues have been identified and discussed in the literature regarding Indigenous participation in business education. These include the under-representation of students in year 12 studies and the role of teachers in guiding and advising students toward careers and opportunities as a result of education in business studies (Lombardi \& Clayton, 2006; Rkein \& Norris, 2012). Business subjects may also be shunned because they are predominantly numeracy-based and support from teachers may be lacking if they believe their students do not have the necessary math level required in courses such as accountancy and finance.

A further issue is derived from the cultural differences between the concept of business in Western and in Indigenous systems (see e.g., Lombardi \& Clayton, 2006; Morley, 2014; Pearson \& Chatterjee, 2010; Rkein \& Norris, 2012). As an example, Indigenous students may find the basic concepts on which the Western accounting system is based totally alienating and culturally insensitive (Rkein \& Norris, 2012). Western accounting systems report on 'wealth accumulation in a capitalist society', which conflicts with the underpinnings of Indigenous societal systems with an obligation to share with community (Lombardi and Clayton, 2006; Rkein \& Norris, 2012). Other examples have been cited for economic models (Morley, 2014) and human resource management concepts (Pearson and Chatterjee 2010).

Indigenous students also lack exposure to business professions in their day-to-day lives and are not familiar with many of the roles and opportunities available in the field of business. This is exacerbated in regional areas where Indigenous people are much less likely to be selfemployed (Productivity Commission, 2009).

\section{Strategies to improve participation in higher education}

Strategies to improve Indigenous participation in higher education range from individual to community based with most authors in the area advocating for 'holistic support structures' (Andersen et al., 2008; White, Frawley \& Dang, 2013, p. 42). There have also been recommendations for peer support networks (Asmar, et al., 2011; Barney, 2013; White et al., 2013) and stronger partnerships between Universities, Schools and other institutions (Hossain, et al., 2008; Wilks \& Wilson, 2012). This can include targeted pathway programs, mentoring programs and early intervention and targeted skill development (Kinnane et al, 2013).

Based on the literature review and taking into account the issues raised above, a program was developed with a view to engage Indigenous students to expose them to business activities and expand their understanding of career opportunities and roles available in business. The theoretical basis for the development of the program was based in the principles of acknowledging Indigenous culture and knowledge - or "Indigenising the curriculum" (Nakata, 2007). Howlett et al. (2008) refer to a "negotiated space between Indigenous knowledge systems and Eurocentric knowledge systems" (p.25). This is achieved through engagement with Indigenous people, consideration for their philosophical stance on issues and recognition of Indigenous knowledge systems (White et al., 2013). The program also established a sense of cultural safety (Barney, 2013; Rahman, 2014) through the inclusion of Indigenous staff who had backgrounds in secondary teaching, in developing resources specific to the task and 
workshop, collaboration with the local Koorie Centre and by including both Indigenous and non-Indigenous speakers and case studies of Indigenous businesses and entrepreneurs. The program was referred to as 'Getting Down to Business'.

\section{'Getting Down to Business' Project}

'Getting Down to Business' is an innovative resource that aims to engage Indigenous secondary students in business education and entrepreneurship, with the intention of encouraging them to undertake further study in business degrees at tertiary level. Focusing on entrepreneurship, the kit introduces students to a variety of successful entrepreneurs and business-people from Aboriginal, Torres Strait Islands and diverse backgrounds, and through the use of exemplars, develop a stronger understanding of core business concepts while increasing students' awareness of the dispositions necessary for succeeding in the world of business.

In the early stages of the project, interviews were conducted with Indigenous entrepreneurs to gain insight into their personal journey to becoming a business. These stories were then developed into case studies with each case study being selected based on the area and genre of the business they inhabited. Each of the case studies was also matched to an area of study within units one or two of the Victorian Curriculum and Assessment Authority's Business Management Study Design (VCAA). Whilst case studies were accompanied by curriculum activities created in line with the VCAA Study Design, the content supports Victorian Essential Learning Standards (AusVELS) level 10 Economics. In order to facilitate students' different levels of learning, it was important to include both AusVELS and the VCAA curricula. However, the lesson samples are predominantly linked to the Victorian Curriculum Assessment Authority's Business Studies units 1 and 2 curriculum, and are intended for a year 10 and year 11 business related audience that possesses prior knowledge of the subject. The resource was not developed to act as a curriculum, rather complement existing curricula within the classroom that allows the content to be modified.

The pedagogical approaches encouraged in the resource have been informed by the literature review, and emphasises an engaging student-centred approach which engages the students in higher order thinking, authentic learning activities and assessment, collaborative and independent learning opportunities and students working in different intelligence areas. Although the projects' key focus was to engage young Indigenous students in business related studies, the resource has been developed to suit students of all cultural backgrounds allowing the kit to be used in any classroom. The kit consists of a 22-page PDF booklet designed for distribution to School Teachers and includes the following:

- An introduction for teachers

- Curriculum links to ausVELS and VCAA

- 5 case studies featuring entrepreneurs and business people

- 5 Sample teaching and learning activities

- 3 projects focusing on small, medium and large scaled businesses

- List of further resources relating specifically to resource

- Links for teachers and students relating to business studies at La Trobe University

The resource kit has been made available online via the La Trobe University website, as well as electronically distributed to all project stakeholders and networks. To support the activities in the resource kit an event was also built into the program. 


\section{'A Day in the City' event}

The second focal point of the project was the creation and execution of an authentic and practical learning experience for Indigenous secondary students, one that introduced students to the world of business. The event took the form of a one-day event held at La Trobe Business School Melbourne's CBD campus in Collins Street Melbourne. On the basis that few Indigenous students have an opportunity to see inside businesses in a major city the event was designed to expose students to a number of different areas of business through group workshops, visits to businesses and talking to several Indigenous entrepreneurs who were willing to share their personal journeys in their business careers. Through the use of exemplars, students developed an understanding of core business concepts in business management while increasing their awareness of the dispositions necessary for succeeding in tertiary education.

Support for this phase of the project was enlisted from business organisations that would potentially provide ongoing support for the programs' continuation - this support was found with the Indigenous Accountants Australia and the Institute of Chartered Accountants Australia and New Zealand. Furthermore, the event allowed La Trobe University's Faculty of Business, Economics and Law to create education links to tertiary studies that will facilitate the students' progression to tertiary level.

Table 1: A Day in the City: Key project details

\section{Project Aims}

- To provide students with an introduction to the world of business

- To provide students with an opportunity to interact with people from the business community

- To introduce students to educational pathways to business degrees at university

- To have students reflect on their personal pathway to tertiary education and careers in business

\section{Participants}

- Thirteen Year 9 and VCAL students from two regional centres in Victoria

Presenters

- One academic, three indigenous business operators, one secondary teacher

Businesses

- 5 case studies, one video presentation, one CBD office visit, one CBD campus experience

Overall feedback (rated on a scale of 1, Highly Disagree to 5, Highly Agree)

- Today was stimulating and enjoyable - 4.2 / 5

- I learnt valuable information about business - 4.4 / 5

- I learnt valuable information about university -4.5 / 5

\section{Delivery}

The A Day in the City project involved 13 Indigenous students from low socio-economic secondary schools from regional centres in Victoria. The cohort included students from one year 9 class and one Victorian Certificate of Applied Learning (VCAL) class. With such diversity 
in both maturity and age of participants, students were seeking varied learning experiences and had various reasons for attending the event.

To support the diverse student audience of the day, several distinct guests were invited to facilitate and support the varied student learning experiences during the event. Guest speakers were chosen in relation to their field of work that would effectively correlate with areas of business and higher education. Guests of the event included an Indigenous Business Association representative, two Indigenous entrepreneurs and small-business owners, La Trobe Business School academic, Indigenous Elders and Koorie Support Officers, as well as several education representatives. The guest speakers engaged the students in different modes of communication through group conversation, presentations and a pre-recorded video by one Indigenous guest who was unable to attend the event.

\section{Evaluation}

Students provided feedback at the end of the session by way of completing a short feedback form. Twelve of the thirteen students provided responses to anonymous short fixed option and open answer questions. In addition comments made by attending teachers and presenters were captured by the organisers and noted. The feedback was summarised and qualitative responses analysed for themes and suggestions. Ethical considerations included ensuring all participants in the project were aware the project was a pilot and that any information provided by respondents was voluntary and anonymous. Clearance was also obtained for photos that recorded some of the activities.

'A Day in the City' event was considered successful and concluded with positive feedback from secondary school staff and students, as well as guest speakers and La Trobe University staff. All the participants were able to gain some insight into the world of business and tertiary studies through exposure of each diverse area and profession. At the conclusion of the event, students provided positive responses toward university study and for some it was not necessarily in business. Comments such as "Uni sounds good as I would like to go one time" (VCAL student 1) and "I would love to go to attend Uni, but maybe study something else [besides business]" (VCAL student 2). One student indicated their future plans were to study "law or para-medicine" (Year 9 student 1). A number of students demonstrated positive attitudes toward business and business education - "[l'd like] more insight [into] people's business and buildings... it's more important than I thought" (Year 9 student 2). Another indicated that "studying business can give you a lot of opportunity, so I won't take my business class so lightly" (Year 11, VCAL student). An aspiration to be a business owner was also mentioned "I'd like to own my own restaurant" (Year 9 student 2) and "If I try hard and get far in life, I could have my own business" (Year 10 student).

Students also provided feedback on their experience and indicated they were strongly engaged with the guest speaker presentations and guest speaker workshops indicating how indigenous culture was incorporated through the role models and storytelling. When asked what they liked best about these events several of the students mentioned a particular mentor. "[He] was really good and made me actually consider going to Uni" (Year 9 student 3), while another liked "getting to meet [him] and going to his work" (Year 9 student 4). They also highlighted how the mentor was able to relate to them personally - "Some of the stories I heard, I had done two business things like this before and there pretty much all the same. But to me [he] and the way he talked and explained things was good and the best part" (Year 11 VCAL student).

As a result students felt more inspired and confident toward future plans, regardless of whether these included business. "The information that [the mentor] had told was inspiring and gave me a better perspective about extending my goals and be the best for my ability (Year 10 student) 
and when asked about the most valuable information from the day, one student responded "that everyone can be what they want and [do] business" (Year 9, student 1). The students also indicated that future events should include more applied learning activities such as visits to more businesses within the CBD and more opportunities to talk with real-world business entrepreneurs. Overall the impact was positive and can be summed up in the following quote - "It influences the younger generations to continue on a great journey and thrive" (Year 10 student).

\section{Discussion and recommendations}

'Getting Down to Business' included a two-pronged approach to engaging Indigenous students. The first enlisted teachers and provided them a resource they could incorporate into their curriculum and featured case studies and examples of successful Indigenous entrepreneurs. The second aspect featured a hands-on excursion to the Melbourne CBD where students experienced life in the business centre. By visiting businesses with Indigenous staff, the students were exposed to a range of career opportunities and gained an understanding of work in a business environment.

The two-pronged approach provided the project team several insights that will be applied to future delivery of the event and resources. The development of the resource kit emphasises the role of secondary teachers in preparing Indigenous students toward business studies as observed in the literature (Lombardi \& Clayton, 2006; Rkein \& Norris, 2012). The practical experience in 'A Day in the City', accompanied with the presence of Indigenous business role models throughout the project, reflects a recognition of the importance of promoting Indigenous cultural identity and Indigenous knowledge system. This could help overcome issues with the "hidden curriculum" and contribute to ensure 'cultural safety' (Rahman, 2013), reducing key barriers to Indigenous participation in higher education.

However, the project achievements were found to be limited due to several institutional constraints and have implications for the design of future initiatives. First, the project was facilitated through the offices of the Faculty of Business, Economics and Law. While this enabled the project to be established quickly and linked closely to a recognised need for improving participation by Indigenous students in business, it was recognised to lack the resources and institutional knowledge available through other areas of the University including the outreach programs.

The University's School Partnerships Program works with schools to provide extra curriculum support, academic preparation and raise awareness of tertiary education and partnerships have been formed with many metropolitan and regional schools. If the project were to be part of this scheme, schools within the existing partnerships would have prior knowledge of the projects' contents and planning would commence earlier with more effective communication could occur between schools. The project's main concern was in developing an understanding that business can be extended to many different disciplines. As such, teachers need to be shown that the project can support their curriculum and it is relevant to their students' present and future education. By working more intensively with schools on professional development in areas such as supporting student transition to higher education and the importance of cocurricular activities during secondary school, it is believed the program will be able to function more efficiently and be more of value to students.

One of the limitations of having two different age groups attending the 'A Day in the City' event was that the middle years students were looking to gain more information regarding the types of businesses and different fields of business that exist, whereas the senior students wanted to gain more information about tertiary studies and more specifically what courses and assistance 
was available to them. Consideration for the needs of different student cohorts should be incorporated into such programs. Focusing on specific learning objectives will allow students to grasp year level appropriate information that will essentially assist their understanding of business studies and tertiary education. Personalising each student's experience is key to sustaining involvement and engagement and this will fundamentally encourage students when building pathways to tertiary education and beyond.

This project also found there needed to be several practical learning workshops to support differentiated student experiences. By providing a number of co-curricular activities, the project can ensure the expression of potential capacities of each individual participant. For all the students attending the event for this project, and consistent with the literature related to preparation for university study, the team identified a lack of university readiness and understanding of opportunities available through university study. The literature review found that like other students from low SES backgrounds, Indigenous students often enter higher education "with little familiarity with academic culture and discourses and, as a result, they can feel ill-prepared and out of place" (McKay \& Devlin, 2014, p. 1). Through classroom activities that have been developed with a business school background, engagement with teachers and support for practical hands on events awareness and aspirations for tertiary education can be raised.

\section{Conclusion}

The Getting Down to Business project saw the development and design of an innovative resource kit, engagement with school teachers and a successful business orientated learning experience delivered for regional Victorian Indigenous students that included Indigenous entrepreneurs, mentors and business people. Limitations identified in the program included having it based in a Business Faculty resulting in a lack of resources and institutional knowledge in relation to outreach programs and by including two different age groups at the workshop which created issues in applying generic learning objectives whereas focused learning objectives for different age groups would be more appropriate. In terms of successes the inclusion of Indigenous entrepreneurs and secondary teachers who acted as role models and gave personal experiences related to their culture and by having hands-on activities that inspired students to take business as a serious and viable career opportunity resulted in changes in attitude toward study and education in general.

A further implication from this project was to include students for a young age, such as Year 7. The younger students were found to have a perspective and a voice. They spoke highly of their experience in visiting the city, specific businesses and the mentor's story which promoted cultural identity.

The findings from this project provide insights and a model for other higher education contexts aiming to improve Indigenous student participation in business education. The approach highlights the need to incorporate Indigenous knowledge, cultural values and establish cultural safety into programs. This can be done through the inclusion of Indigenous mentors, Elders and others from the community to inspire students and future leaders (Dang, 2014). The issue of low participation rates for business education at the tertiary level is complex and should be addressed by a holistic, complex and coherent approach and by viewing Indigenous participation at multiple levels as part of the solution. 


\section{References}

Andersen, C., Bunda, T., \& Walter, M. (2008). Indigenous higher education: the role of universities in releasing the potential. The Australian Journal of Indigenous Education, 37(01), 1-8.

Asmar, C., Page, S., \& Radloff, A. (2011). Dispelling myths: Indigenous students' engagement with university. AUSSE Research Briefing (ACER), 10, 1-15.

Australian Bureau of Statistics (ABS). (2012). Census of Population and Housing: Characteristics of Aboriginal and Torres Strait Islander Australians, 2011. Retrieved 21 November 2014, from http:// www.abs.gov.au/ausstats/abs@.nsf/Lookup/2076.0main+features302011.

Barney, K. (2013). 'Taking your mob with you': Giving voice to the experiences of Indigenous Australian postgraduate students. Higher Education Research \& Development, 32(4), 515-528.

Behrendt, L., Larkin, S., Griew, R., \& Kelly, P. (2012). Review of higher education access and outcomes for Aboriginal and Torres Strait Islander people, final report. Retrieved from http://www.innovation. gov.au/highereducation/IndigenousHigherEducation/ReviewOfIndigenousHigherEducation/ FinalReport/IHERFinalReport.pdf.

Biddle, N. (2010). A human capital approach to the educational marginalisation of Indigenous Australians. The Australian National University: Centre for Aboriginal Economic Policy Research.

Bradley, D., Noonan, P., Nugent, H., \& Scales, B. (2008). Review of Australian Higher Education Final Report. Retrieved from http://www. deewr.gov.au/HigherEducation/Review/Documents/PDF/ Higher\%20Education\%20Review_one\%20document_02.pdf.

Chirgwin, S.K. (2014). Burdens too difficult to carry? A case study of three academically able Indigenous Australian Masters students who had to withdraw. International Journal of Qualitative Studies in Education (ahead-of-print), 1-16.

Department of Education (2014) Selected Higher Education Statistics - 2013 Student Data. Accessed 31 May 2015 from: https://education.gov.au/selected-higher-education-statistics-2013-student-data.

Dang, T.K.A. (2014). Indigenous Youth Leadership Programs: National and International Perspectives. Unpublished commissioned report, Centre for Indigenous Education and Research, Australian Catholic University, Australia.

Foley, D. (2013). Jus Sanguinis: The root of contention in determining what is an Australian Aboriginal business. Indigenous Law Bulletin, 8(8), 25-29.

Hossain, D., Gorman, D., Williams-Mozely, J., \& Garvey, D. (2008). Bridging the gap: Identifying needs and aspirations of Indigenous students to facilitate their entry into university. The Australian Journal of Indigenous Education, 37(1), 9-17.

Kinnane, S., Wilks, J., Wilson, K., Hughes, T. \& Thomas, S. (2013). 'Can't be what you can't see': The Transition of Aboriginal and Torres Strait Islander Students into higher education. Final Report, OLT. Sydney, Australia: Department of Education.

Lombardi, L., \& Clayton, B. (2006). Indigenous Australian accountants: why so few? A historical and cultural perspective. Global business \& economics anthology, 1, 63-74.

McKay, J., \& Devlin, M. (2014). 'Uni has a different language.... to the real world': demystifying academic culture and discourse for students from low socioeconomic backgrounds. Higher Education Research \& Development (ahead-of-print), 1-13.

Morley, S. (2014). Success factors for Indigenous entrepreneurs and community-based enterprises. Resource sheet no. 30 produced for the Closing the Gap Clearinghouse.

Pearson, C.A., \& Chatterjee, S.R. (2010). Extending business education beyond traditional boundaries: A case study in negotiated problem resolution in a remote regional indigenous community in Australia. Journal of Teaching in International Business, 21(4), 307-328. 
Pechenkina, E., \& Anderson, I. (2011). Consultation paper on Indigenous Australian Higher Education: Trends, Initiatives and Policy Implications. Prepared for the Review of Higher Education Access and Outcomes for Aboriginal and Torres Strait Islander People, Commissioned Research Paper No. 1, Commonwealth of Australia.

Productivity Commission (2009). Overcoming Indigenous Disadvantage: Key Indicators 2009. Retrieved from http://www.pc.gov.au/gsp/reports/indigenous/keyindicators2009.

Raciti, M., Powell, B., Czok, C., \& Copley, N. (2014). Developing school-to-university pathways for Aboriginal and Torres Strait Islander peoples: A social marketing case study. Paper presented at the Proceedings of the 2014 Australian and New Zealand Marketing Academy Conference.

Rahman, K. (2013). Belonging and learning to belong in school: the implications of the hidden curriculum for indigenous students. Discourse: Studies in the Cultural Politics of Education, 34(5), 660-672.

Rkein, H.I., \& Norris, G. (2012). Barriers to Accounting: Australian Indigenous Students' Experience. Social and Environmental Accountability Journal, 32(2), 95-107.

Schwab, R.G. (1996). Indigenous participation in higher education: Culture, choice and human capital theory. Discussion Paper No. 122. The Australian National University: Centre for Aboriginal Economic Policy Research.

White, N., Frawley, J., \& Dang, T.K.A. (2013). Good Practice Report: Innovative Indigenous Teaching and Learning. Sydney, NSW: Office for Learning and Teaching. Retrieved from: http://www.olt.gov.au/ resource-good-practice-report-innovative-indigenous-teaching-and-learning-2013.

Wilks, J., \& Wilson, K. (2012). Going on to uni? Access and participation in university for students from backgrounds of disadvantage. Journal of Higher Education Policy and Management, 34(1), 79-90. 